\title{
Expert Mechatronics System for Fire Crisis Management in Educational Institutions
}

\author{
Ahmed A. A. Kamel \\ Department of Computer Science \\ Mansoura University \\ Egypt
}

\author{
Hosnia M. M. Ahmed \\ Department of Computer Science \\ Mansoura University \\ Egypt
}

\begin{abstract}
The security and protection of educational institutions from fire is a major challenge at the present time. However, advanced technologies can be of a great help in this regard, especially embedded systems and mechatronics, which has become a hot research topic as regard meeting those challenges. Hence, this paper presents a novel and effective expert mechatronics system to manage fire crises in educational institutions. The system provides solution for the problem of predicting fires before they break and how to prevent and manage them, to save lives and property. The system begins with obtaining data by measuring symmetrical physical quantities from the surrounding environment (temperature, gas, smoke, flames, and fire) using sensors. After then, the controller processes the data received from these sensors. In addition, data received from sensors are sent to the expert system to manage them and provide required suggestions and recommendations to manage the existing crisis. In the unsafe condition, such as the spread of gas or smoke smell or fire, the actuators will be activated and the proposed system will release two types of warning signals: an audio signal using sound alarms, and a visual one using red and yellow lights. Moreover, the system sends an SMS to the System Manager and decision makers in the educational institution about the secured place with information and details on the fire and its location. The proposed system was tested by fabricating different fire crisis instances. The performance of proposed system was evaluated in terms of the confusion matrix including parameters such as Precision, Sensitivity, Specificity, F-measure, Error Rate and Accuracy The findings show that the proposed system is effective and usable.
\end{abstract}

Keywords-Mechatronic; Expert Systems; Crisis Management; Arduino.

\section{INTRODUCTION}

The past decades have witnessed technological development relentless that led to advancing in devices, machines, processes, and systems by enhancing their performance and creating new value and function [1]. In the last years, we noticed the transformation in these functions from mechanics to electronics followed by wider and new functions as in system development by specific or autonomous intelligent functions [2], [3]. Mechatronics, robotics, and embedded systems have become hot research areas for the sustainable development of an intelligent and autonomous system [4]. An embedded system is a computer-based system designed to perform several specific functions in real-time [5]. On the other hand, embedded computing systems (ECSs) are computer systems that have hardware supplied with embedded software as one of their components [6]. The integration between the components (hardware) and the information-driven function (software) produces embedded systems that are called mechatronic systems [3], [7]. Mechatronics is Smart components and devices characterized by an integration of technologies and a transfer of functionality from the mechanical to the electronics and software domains [2]. A mechatronic system is an intelligent mechanical system. Mechatronics represent an approach that aims at the synergistic integration of control theory, mechanics, electronics and computer science in order to improve the functionality of systems or processes [8]. The development of mechatronic systems includes an optimal balance between the basic mechanical structure, sensor and actuator implementation, automatic digital information processing and overall control, This synergy leads to innovative solutions to design products with built-in intelligence [3], [9]. Thus, mechatronics is an interdisciplinary field where the following disciplines act together: mechanical systems including machines, mechanical elements and precision mechanics, electronic systems including power electronics, microelectronics and actuator technology and information technology including control and automation, systems theory, artificial intelligence and software engineering. This is shown in Fig. 1 [9], [10].

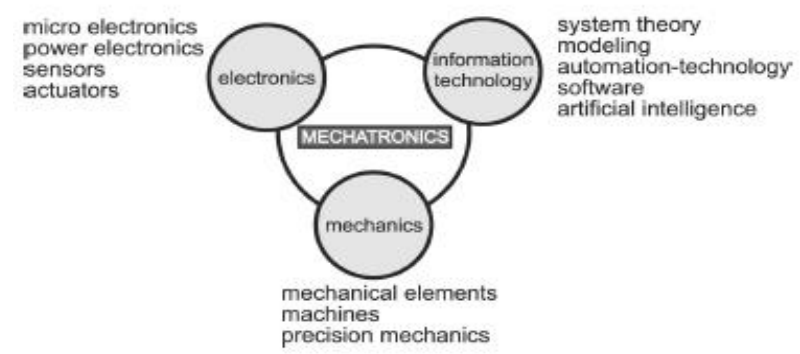

Fig 1: Mechatronics: synergetic integration of different disciplines

The techniques of artificial intelligence and expert systems are most probably that make increasingly significant contribution to all aspects of mechatronics in the next years [11]. With the rapid growth in artificial intelligence technology and mechatronic systems, this technology advancement in general should combine with recent trends either in our homes, factories or in our institutions especially educational institutions [12], [13] to provide effective and appropriate security systems. It is noteworthy that educational institutions are witnessing multiple serious crises that threatens functioning and performance such as earthquakes, twisters, floods, terrorist attacks, sabotage and different accidents that occur suddenly and will have severe 
destructive effects unless they are addressed immediately [14] but the most devastating crises are fire crises. Fire crisis is a common threat to life and institutions, including educational institutions [15]. Crisis management is a management model applied in extra-ordinary situations [16]. It is a proactive process which involves dealing with the crisis before it happens, during the crisis and after it happens in order to overcome it with a minimal damage [17]. Effective crisis management involves five key activities of response: signal detection, prevention, damage control, recovery, and learning [18]. One of the most important processes in crisis management is to establish an early warning system for crisis especially fire crisis this contributes to hinder the occurrence of the crisis and to survive without huge financial losses also provides some time to take the required precautions against potential crises [16]. Appropriate security procedures are essential for the regular operation of different institutions, especially educational institutions. Without security procedures, an institution will be unsafe and will not be able to perform its daily operations and activities such as education programs. Until now, many of educational institutions use traditional methods to secure their facilities against fire, so this makes them to face many other crises. Hence, the need for computerized crisis management systems has grown significantly over time. Developments in technologies such as artificial intelligence (AI) and innovations in areas like robotics, mechatronics, semantic web and multi-agent systems create new opportunities to enhance disaster and risk reduction. In addition, they can be useful for solving crisis response problems and improving the efficiency of the crisis management process, especially fire crisis [19], [20]. Mechatronic devices will present enhanced safety and security systems [11] to protect from and manage fires, especially in educational institutions. In this study, the expert mechatronics system is used as an important and powerful tool to help the managers of educational institutions manage fire crises. These systems can monitor the spread of smoke, flames, gases and heat releases, provide diagnosis to forecast fires and prevent them, and transmit vital signals to ambulance crews, the fire department and the managers of the educational institution. Thus, they protect lives and property, which is the aim of the system proposed in the current study. In view of this, the current study presents a novel expert mechatronic system for the management of fire crises in educational institutions. The remaining part of this paper is organized as follows: Section 2 discusses the structure of the proposed mechatronic system; Section 3 analyses the performance of the proposed system while Section 4 presents the conclusion.

\section{THE STRUCTURE OF PROPOSED MECHATRONIC SYSTEM}

The proposed Mechatronic system was designed to manage fire crisis in educational institutions. The system depends on two basic aspects: hardware integration and programming and the development of the expert system. This structure is shown in Fig. 2.

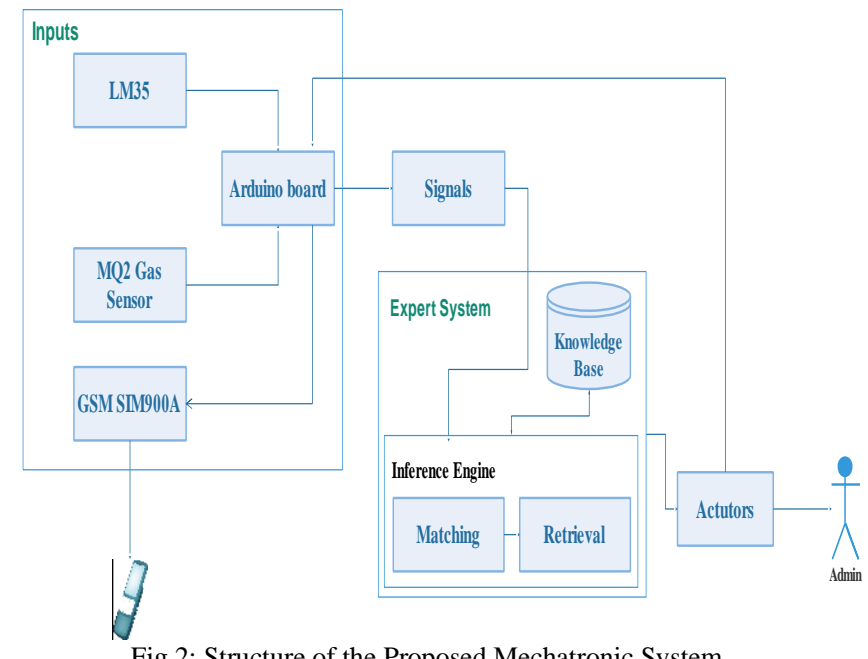

A. Hardware integration and programming:

Hardware integration results from designing the mechatronic system as an overall system and embedding the sensors, actuators and microcomputers/ microcontrollers into the mechanical system. In the following section, we present a brief about hardware used in the proposed system. The Arduino UNO board (Microcontroller) is a custom designed printed circuit board that could be used for various mechatronics applications. Fig. 3. Shows the Arduino Uno (ATmega 328P). It is an open source device, a prototyping board consisting of ATmega 328P microcontroller providing a $5 \mathrm{~V}$ and $3.3 \mathrm{~V}$ output voltage option. It takes input voltage either from USB connection to the computer or a coaxial cable using a portable power supply. On the Arduino Microcontroller, sketches can be uploaded using Arduino IDE (Integrated Development Environment). It has 14 digital input/output pins (of which 6 can be used as PWM outputs), 6 analog inputs, a $16 \mathrm{MHZ}$ crystal oscillator, a USB connection, a power jack, an ICSP header, and a reset button. It contains everything needed to support the microcontroller. Simply connect it to a computer with a USB cable or power it with an AC-to- DC adapter or battery to get started. It takes input voltage in between $7-12 \mathrm{~V}$ [21].

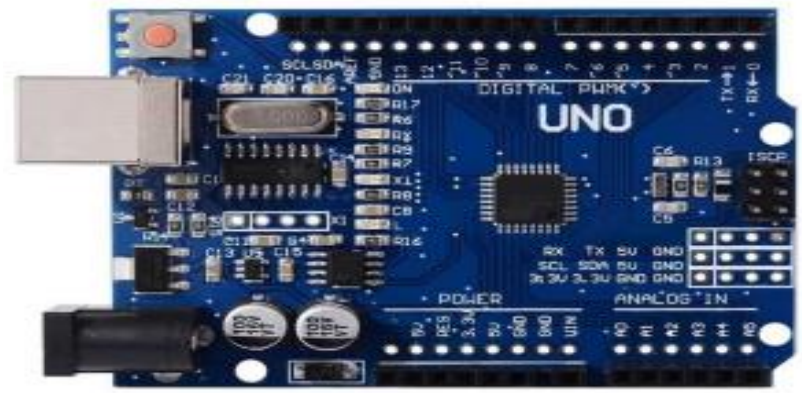

Fig 3: Arduino Uno (ATmega 328P)

The multisensory unit contains sensors that detect fire. The proposed system contains two kinds of sensors: Temperature sensor (LM 35) and MQ-2 Gas sensor. In the following section, we present a brief description of the sensors used in the proposed system. LM35sensor is used to measure precise centigrade temperature. The output of this sensor describes the linearity. The output voltages of this sensor are linearly 
comparative to the Celsius temperature [22]. LM35 directly connected to Arduino. The output of LM35 temperature goes to comparator circuit and used for over temperature indication or by using a simple relay, used as a temperature controller [23], [24]. LM35 has three Pinouts Fig .4. Which are (GND, VCC, AOUT) [23], table.1 show as LM35 Pinout.

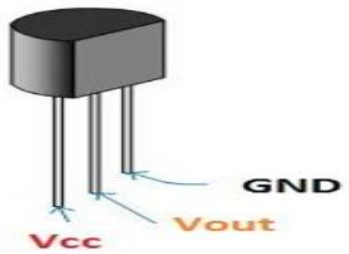

Fig 4: LM35 sensor

Table.1 LM35 Pinout

\begin{tabular}{|c|c|c|}
\hline Pin & Description & Function \\
\hline GND & Ground & Connected to 0V or GND \\
\hline VCC & Power & Connected to +5V \\
\hline AOUT & Output & $\begin{array}{c}\text { It should be connected with an analog } \\
\text { pin of Microcontroller }\end{array}$ \\
\hline
\end{tabular}

After getting analog value at analog pin we reads that value using analog read function and stores that value in a variable. And then by applying given formula converts it in temperature [24]. The following Fig. 5. shows programming algorithms for LM35 sensor.

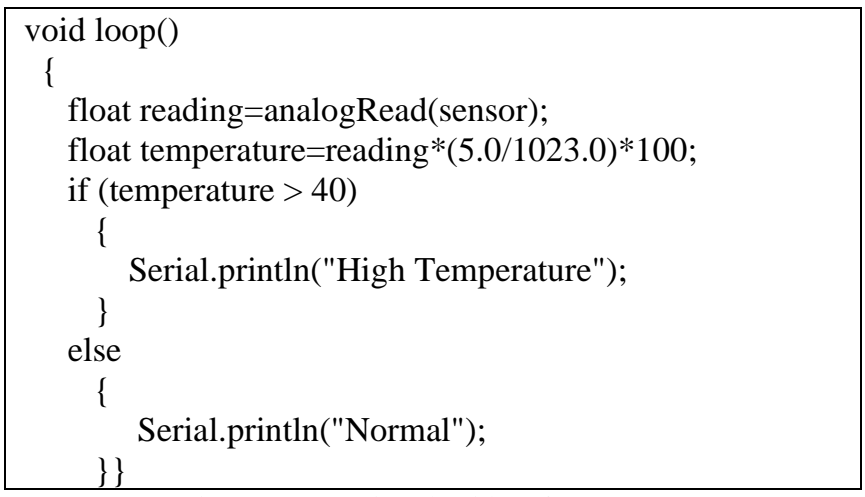

Fig.5: Programming algorithms for LM35 sensor

The MQ-2 Gas sensor is sensitive to smoke and is used to detect gas level around the area [25]. This sensor can be used for homes; factories or educational institutions gas leak monitoring. It is suitable for gas, butane, propane, methane, alcohol, hydrogen, smoke and other monitoring devices [26]. MQ2 has four Pinouts Fig. 6. Which are (GND, DOUT, AOUT, VCC) [27], table.2 show as MQ2 Pinout.

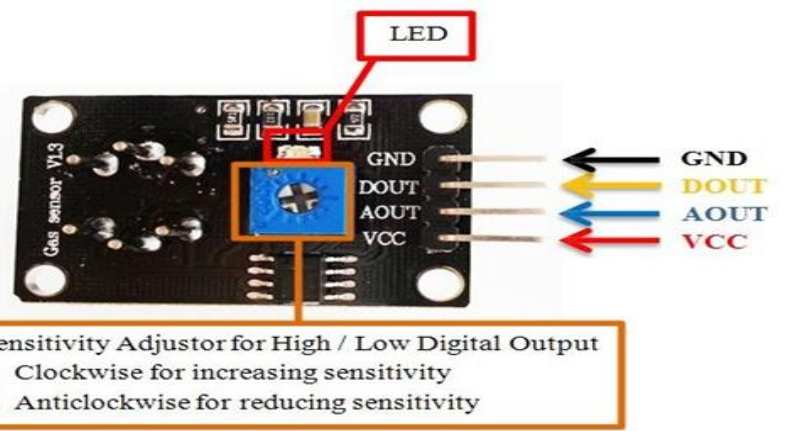

Fig 6: MQ-2 Gas sensor
Table.2 MQ-2 Pinout

\begin{tabular}{|c|c|c|}
\hline Pin & Description & Function \\
\hline GND & Ground & Connected to $0 \mathrm{~V}$ or GND \\
\hline DOUT & Digital Output & 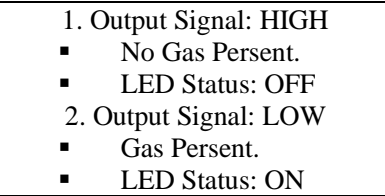 \\
\hline Aout & Analog Output & $\begin{array}{l}\text { The output voltag changing with } \\
\text { the concenttration of surrounding } \\
\text { gas present. } \\
\text { Output Voltage } \\
\text { Increases: Increasing in } \\
\text { concentartion of } \\
\text { surrounding gas. } \\
\text { Output Voltage } \\
\text { Decreases: Dncreasing } \\
\text { in concentartion of } \\
\text { surrounding gas. } \\
\end{array}$ \\
\hline $\mathrm{VCC}$ & Power & Connected to $+5 \mathrm{~V}$ \\
\hline
\end{tabular}

The following Fig. 7. Shows programming algorithms for MQ2-Gas sensor.

int smoke $\mathrm{A} 0=\mathrm{A} 5$;

int sensorThres $=400$; / Threshold value

void $\operatorname{setup}()$

\{

pinMode(smokeA0, INPUT);

Serial.begin(9600); // Setting the baud rate of Serial

Monitor (Arduino)

\}

void loop()

\{

int analogSensor $=$ analogRead $(\operatorname{smokeA} 0)$;

Serial.println(analogSensor);

if (analogSensor > sensorThres)

\{

\}

Serial.println("Fire");

else

\{

\}

Serial.println("Normal");

$\operatorname{delay}(100) ;\}$

Fig 7: Programming algorithms for MQ2-Gas sensor

A GSM modem is a special type of modems that accepts the SIM card and operates through a subscription to a mobile operator such as a mobile phone [28]. As a mobile phone, the GSM modem is used to send and receive SMS messages. Fig.8. Below shows the GSM modem [21].

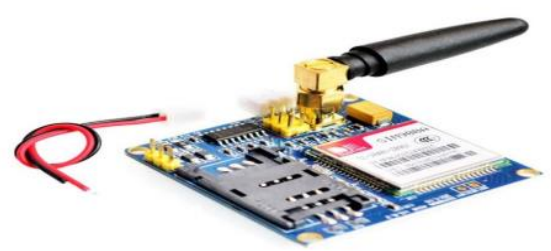

Fig 8: GSM SIM900A

Arduino and GSM module communicate with each other serially. Accordingly, we should use the serial pins of Arduino (Rx and Tx). 
- Tx pin in GSM module is to be connected to Arduino's Rx pin.

- Rx pin in GSM module is to be connected to Arduino's Tx pin.

- The ground pin of GSM should be connected to Arduino's ground pin.

Each time we burn the program to Arduino, we should disconnect the wiring in $\mathrm{Rx}$ and $\mathrm{Tx}$. These pins can be reconnected and we can have the system working, as soon as the program loads successfully. [29].The following Fig. 9. Shows programming algorithms for GSM SIM900A modem.

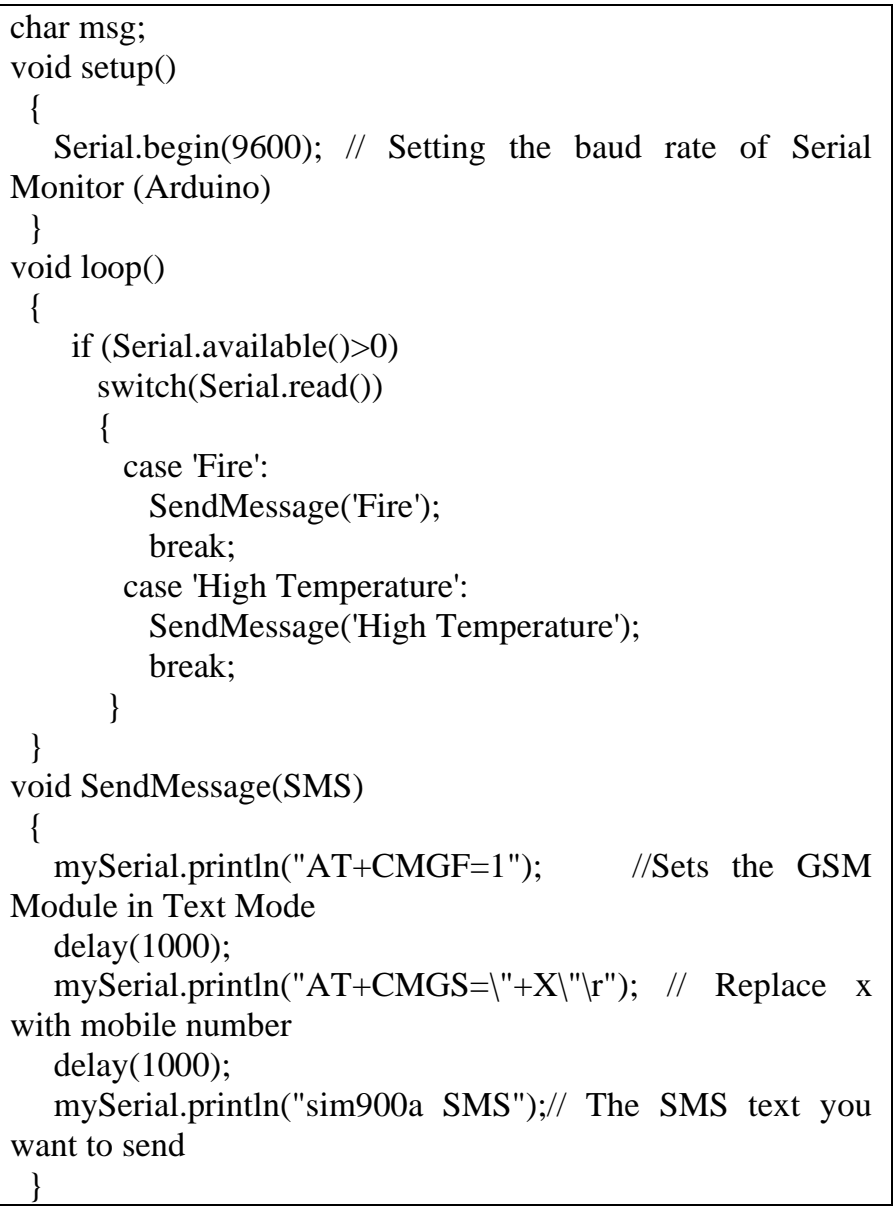

Fig 9: Programming algorithms for GSM SIM 900A

As the sensors produce input to the system, the actuators provide the output to the system that influences the system itself and its environment. The proposed system also includes two types of actuators that are activated during fire detection. The first is an audio actuator that is used as a voice warning system and the other is an optical actuator that is used to produce red and yellow light in unsafe conditions. Thus, we combined between the input system and output system mechanically without human intervention.

\section{B. Development of expert system as an important tool to manage fire crisis}

New trends in the development of artificial intelligence and expert systems and the interest in increasingly more autonomous machines can lead to great progress of existing mechatronic devices [30]. As intelligence is usually embedded in the planning and control sub-system, it relies on the information that is taken from the sensors. Several tools are used in the sub-system for decision making and information processing such as conventional microprocessors, fuzzy logic, artificial neural networks, and probabilistic reasoning [31]. Information processing in a mechatronic system may range from simple control functions to intelligent control systems [9]. In this study, an intelligent control system was designed as a rule-based expert system architecture consisting of three parts: Knowledge base, Inference engine and graphical user interface (GUI).

\section{1) Knowledge base}

The knowledge base is the heart of the expert system [32]. It contains all facts related to the domain and rules that define the way these facts are used [32]. The knowledge base can also contain theories, concepts and heuristic search methods so that it ultimately represents the source of intelligent of the expert system. Expert systems follow many approaches in Knowledge Representation to design the knowledge base such as semantic networks, frames and production rules [33]. Rule representation is regarded as being the best and most common Knowledge representation techniques, as these rules are flexible [34]. The knowledge in the knowledge base is represented as a set of rules. Rule base consists of two parts as antecedent and consequent. The first part of the rule specifies the condition part with 'if', and the second part specifies the result with "then" When the IF-part of the rule is achieved, the THEN-part is executed [35], [36]. The knowledge base of the proposed system includes the highly specialized knowledge in the fire management in the form of experimental rules. Fig. 10. Shows a series of IF-THEN rules have been used to describe the I / O layout of the proposed system:

val = digitalRead(PIRPin);

if $(\mathrm{val}==\mathrm{HIGH})$

\{

digitalWrite(ledPin, $\mathrm{HIGH})$;

delay(150);

if

if $($ pirState $==$ LOW $)$

\{

Serial.println("Motion Detected");

pirState = HIGH;

Fig 10: A series of IF-THEN rules

\section{2) Inference engine}

The inference engine is the knowledge processor and is modeled after the expert's reasoning. It is used to execute the rules and works with available information about a specific problem. It also uses the knowledge stored in the knowledge base to extract conclusions and make decisions [37]. The inference engine performs the reasoning process while the expert system finds a solution [35]. Through the inference engine, the proposed expert system matches facts with rules to retrieve the appropriate case and the required recommendations and suggestions to manage this case. 


\section{3) GUI}

The user interface enables communication between the user and the system. It takes input to the system and presents output to the user [32]. The following sections show some of the proposed system screens. When the system is running, the login window Fig. 11. Will appear. The user enters username and password data and then clicks on "Login".
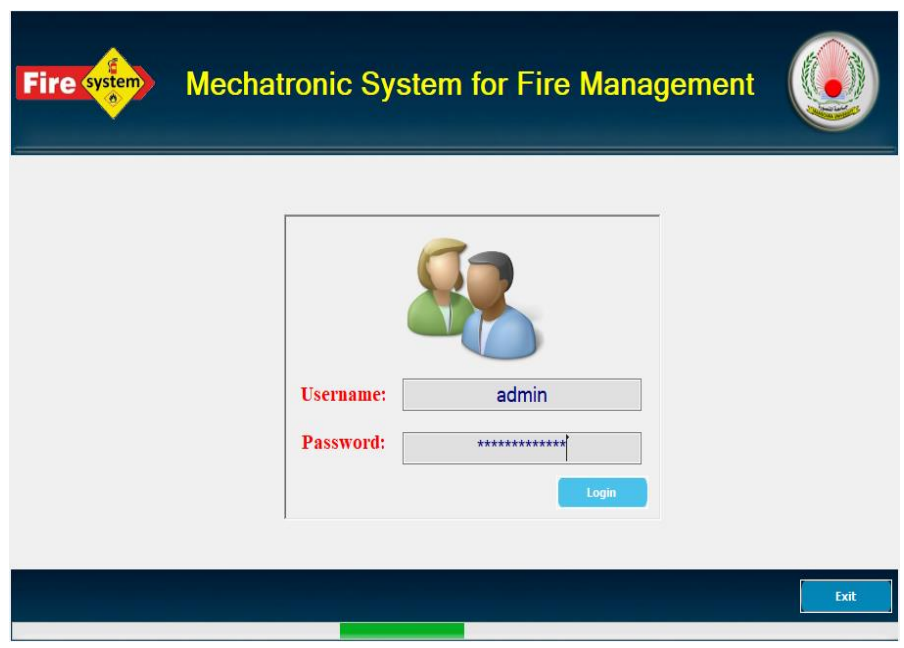

Fig 11: the login window

After logging into the system, the main window Fig. 12. Will appear. The user clicks "Refresh" to show available Serial Comm numbers. The user selects the appropriate port and clicks "Connect".

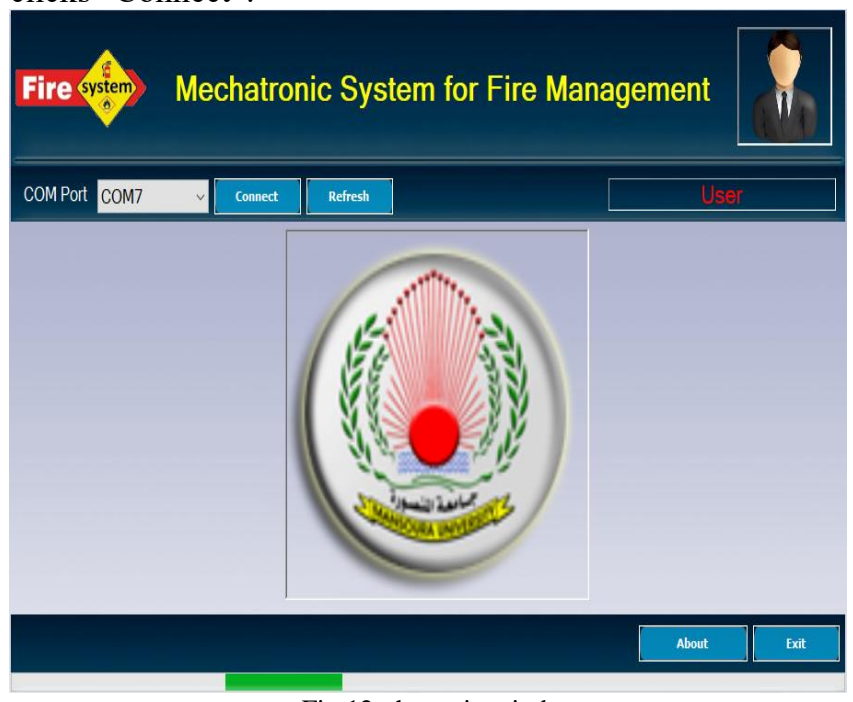

Fig 12: the main window

The system starts and receives the data sent to it by Arduino board, analyses these data and shows the data of the secured places on the main screen. The system has two statuses: First: Safe Condition, Fig. 13. Shows the Safe condition, where the temperature is shown as appropriate and there is no smoke or gas leakage.

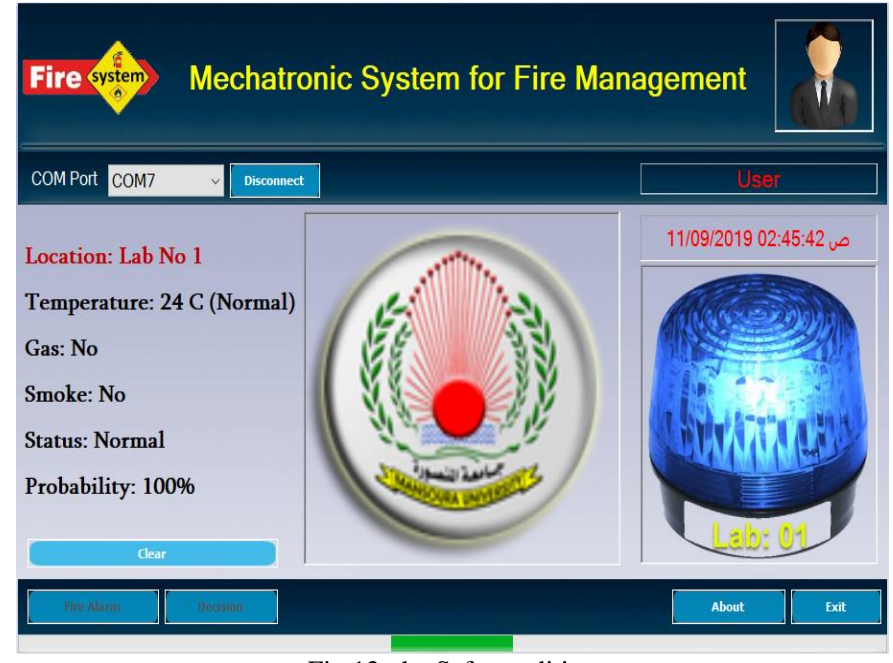

Fig 13: the Safe condition

Second: Unsafe Condition, Fig. 14. Shows the unsafe condition, indicating that the temperature is very high and there is smoke and gives a $96 \%$ probability of fire breaking out. In this case, two kinds of warning signals are released: an audio warning is released through the alarm bells, and a light signal is released through the red and yellow lights. In addition, an SMS is sent to the system manager and the head of the educational institution about the secured place with giving the details of the fire and its location.

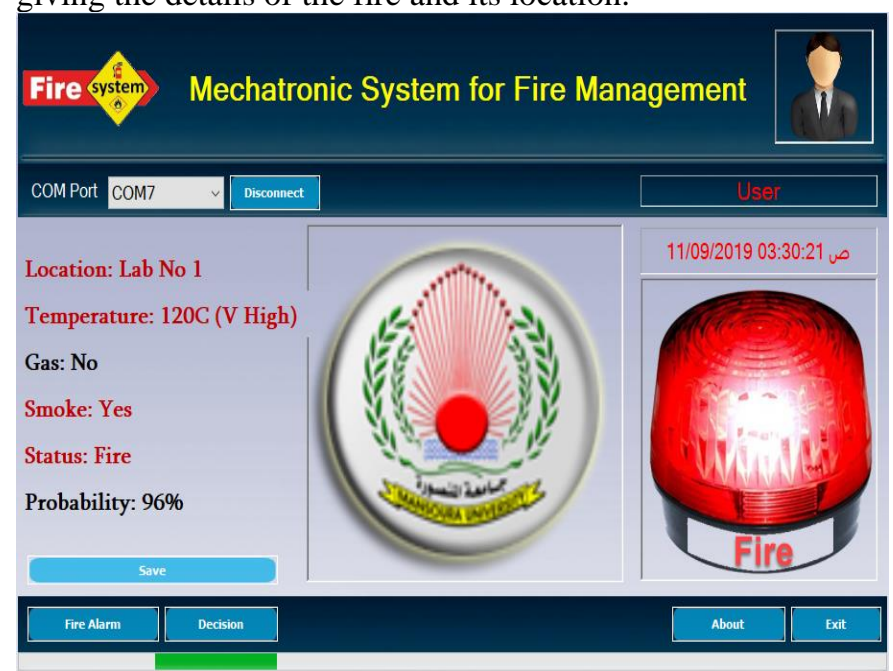

Fig 14: the Unsafe Condition

When the user clicks "Fire Alarm", the window shown in Fig. 15. Will appear with an engineering drawing of the secured place detailing the contents of the place, its exits and entrances, ventilation ports, location of the firefighting system and sites of fire extinguishers. Also, a symbol will appear signalling the site of fire. 


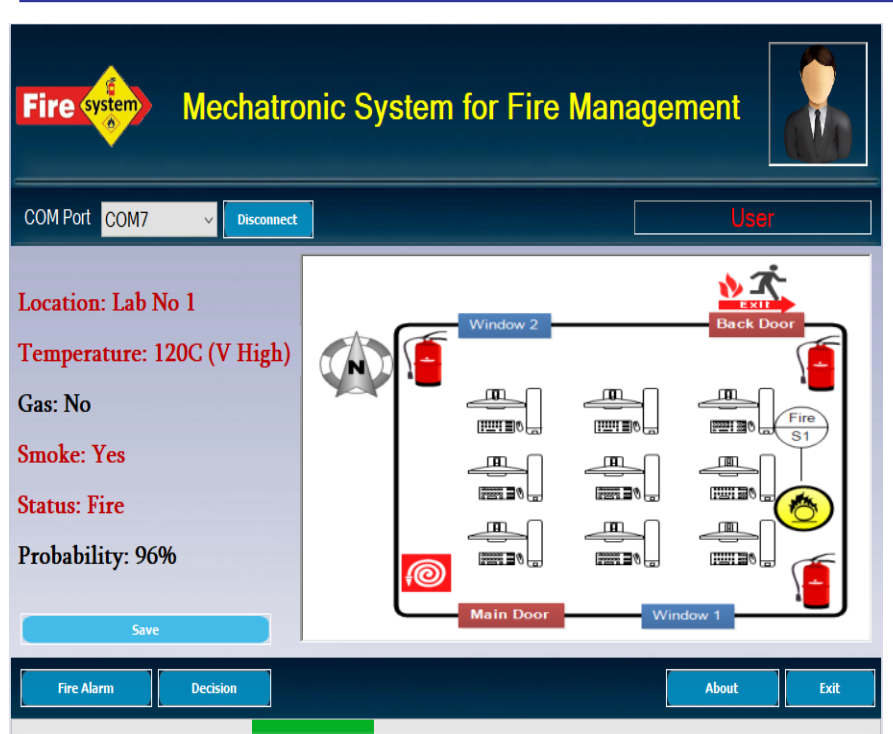

Fig 15: prototype of the secured place

When the user clicks on "Decision", the window shown in Fig. 16. Will appear, presenting the type of fire and the actions and recommendations of the system for this case, to be followed by the firefighting team in the educational institution.

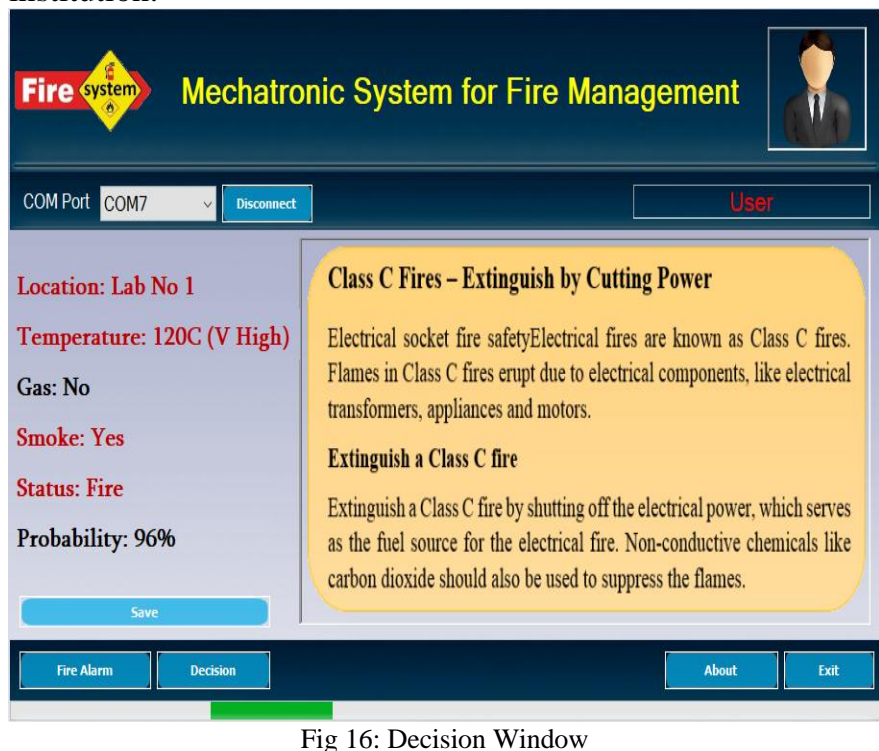

\section{EXPERMENTAL RESULTS}

The proposed system application was developed using VB.NET 2019 and Arduino C language. The algorithm was tested in real environment on 15 cases to ensure the efficiency of the system and its validity for use and measure its performance. The test was divided into three categories: the fire occurrence consisting (five cases) in which the fire is fabricated. The second category ( $\mathrm{H}$ temp) consists of five cases in which the temperature was raised but less than the limit required to start a fire. The third category (Safe) is the safe condition of the system. It also consists of five cases. The following confusion matrix shows the findings of implementation (table.3):

\begin{tabular}{|c|c|c|c|c|}
\hline \multirow{2}{*}{\multicolumn{2}{|c|}{ Confusion Matrix }} & \multicolumn{3}{|c|}{ Predicted } \\
\hline & & \multirow{2}{*}{$\begin{array}{c}\text { Fire } \\
5\end{array}$} & \multirow{2}{*}{$\frac{\text { H Temp }}{0}$} & \multirow{2}{*}{$\frac{\text { Safe }}{0}$} \\
\hline ๘ & Fire & & & \\
\hline 这 & H Temp & 1 & 4 & 0 \\
\hline & Save & 0 & 0 & 5 \\
\hline
\end{tabular}

The performance of the proposed system was evaluated in terms of Precision, Sensitivity, Specificity and F-measure. These measures are derived from the confusion matrix and can be defined as follows [38]:

$$
\begin{gathered}
\text { precision }=\frac{t p}{t p+f p} \\
\text { sensitivity }=\frac{t p}{t p+f n} \\
\text { speciificity }=\frac{t n}{f p+t n} \\
f-\text { measure }=2 * \frac{\text { precision } * \text { sensitivity }}{\text { precision }+ \text { sensitivity }}
\end{gathered}
$$

Where tp: true positive, fp: false positive, fn: false negative and tn: true negative counts. The following table. 4 shows the findings:

Table.4 Confusion Matrix results

\begin{tabular}{|c|c|c|c|c|}
\cline { 2 - 5 } \multicolumn{1}{c|}{} & Fire & H Temp & Save & System \\
\hline Precision & 0.83 & 1.00 & 1.00 & 0.94 \\
\hline Sensitivity & 1.00 & 0.80 & 1.00 & 0.93 \\
\hline Specificity & 0.90 & 1.00 & 1.00 & 0.97 \\
\hline F- measure & 0.91 & 0.89 & 1.00 & 0.93 \\
\hline
\end{tabular}

From the previous table it can be seen that all the results were high and acceptable. Moreover, Accuracy and Error Rate (ERR) were measure for the system as a whole. These measures as defines as [38]:

$$
\begin{gathered}
\text { Accuracy }=\frac{t p+t n}{t p+f p+f n+t n} \\
E R R=\frac{f p+f n}{t p+t n+f n+f p}
\end{gathered}
$$

The following table. 5 shows the findings:

Table.5 Accuracy, ERR for proposed system

\begin{tabular}{|c|c|}
\cline { 2 - 2 } \multicolumn{1}{c|}{} & System \\
\hline Accuracy & 0.93 \\
\hline Error Rate & 0.07 \\
\hline
\end{tabular}

From the above table, the rate of efficiency of the system as a whole was (0.93), which is high, whereas the rate of system error (0.07) which is low. This confirms that the system is suitable for application and use.

\section{CONCLUSIONS}

In this paper, we presented an embedded mechatronic system to manage fires crisis in educations institutions. The system can monitor the spread of smoke, flames, gases and release of heat. It can also provide diagnosis in time to predict fires and prevents them start. The system begins with obtaining data by measuring symmetrical physical quantities from the surrounding environment (temperature, gas, smoke, flames, and fire) using sensors. After then, the controller processes the data received from these sensors. In addition, data 
received from sensors are sent to the expert system to manage them and provide required suggestions and recommendations to manage the existing crisis. In the unsafe condition, such as the spread of gas or smoke smell or fire, the actuators will be activated and the proposed system will release two types of warning signals: an audio signal using sound alarms, and a visual one using red and yellow lights. Moreover, the system sends an SMS to the System Manager and decision makers in the educational institution about the secured place with information and details on the fire and its location. The proposed system was tested by fabricating different fire crisis instances. The performance of the proposed system was evaluated using the confusion matrix (Precision, Sensitivity, Specificity, F-measure, Error Rate and Accuracy). The results demonstrate the effectiveness of the proposed algorithm.

\section{REFERENCES}

[1] H.Cho,"OPTO-MECHATRONICSYSTEMS

HANDBOOK

Techniques and Applications", The Mechanical Engineering Handbook Series, CRC Press LLC, CRC PRESS Boca Raton London New York Washington, D.C, 2003.

[2] S.Watt, C.Milne, D.Bradley, D.Russell, P. Hehenberger, J. Lopez, "Privacy Matters - Issues within Mechatronics", IFACPapersOnLine 49-21 (2016) 423-430.

[3] R. Isermann," Mechatronic systems-Innovative products with embedded control", Control Engineering Practice 16 (2008) 14-29.

[4] Y. Tao, J. Tan, Z. Shao and H. Wei, "Mechatronics and embedded systems 2015", Advances in Mechanical Engineering 2016, Vol.8 (10) $1-2$.

[5] J.PUHAN, "Operating Systems, Embedded Systems, and Real-Time Systems", CIP - Cataloging In Publication National and University Library, Ljubljana, 2015 FE Publishing.

[6] D. Möller, "Guide to Computing Fundamentals in Cyber-Physical Systems Concepts, Design Methods and Applications ", Springer International Publishing Switzerland, 2016.

[7] Z.Chen, Q.Xiansheng, B.Eynard, L.Jing, B.Jing, Z.Yichad, S.Gomes, "Interface model-based configuration design of mechatronic systems for industrial manufacturing applications", Robotics and Computer Integrated Manufacturing 59 (2019) 373-384.

[8] F.A.Salem, A. A.Mahfouz, "Mechatronics Subsystems' Classification, Role, Selection Criteria and Synergistic Integration in Overall System Design", American Journal of Educational Science, Vol. 2, No. 3, 2016, pp. 16-28.

[9] G.Habchin, C.Barthod," An overall methodology for reliability prediction of mechatronic systems design with industrial application", Reliability Engineering and System Safety 155(2016)236-254.

[10] R.H.Bishop, "MECHATRONICS: AN INTRODUCTION", Taylor \& Francis Group, LLC, Library of Congress Cataloging-in-Publication Data, 2006.

[11] D. Bradley and D.W.Russell, "Mechatronics in Action- Case Studies in Mechatronics Applications and Education", Springer-Verlag London Limited 2010

[12] N. Prince. N, N.Ifeanyi. I, E.C.Joseph, "Design and Implementation of Microcontroller Based Security Door System (Using Mobile Phone \& Computer Set)", Journal of Automation and Control Engineering, Vol. 1, No. 1, March 2013

[13] V.C. Moulianitis, G.-A.D. Zachiotis, N.A. Aspragathos, "A new index based on mechatronics abilities for the conceptual design evaluation", Mechatronics 49 (2018) 67-76.

[14] A. R. Krishna, G.S. Bala, A. S.N.Chakravarthy, B. B.P.Sarma, G. S.Alla, " Design of a Rescue Robot Assist at Fire Disaster", International Journal of Computer Applications (0975 - 888), Volume 47- No.10, June 2012.

[15] A.J. John, K.Ashik, A. KS, P.Fahmi, P.Henna, "AUTOMATIC FIRE EXTINGUISHING ROBOTIC VEHICLE", International Journal of Scientific \& Engineering Research, Volume 7, Issue 4, April-2016.

[16] S.Sahin, S. Ulubeylib , A. Kazaza, Innovative Crisis Management in Construction: Approaches and the Process, World Conference on Technology, Innovation and Entrepreneurship , Procedia - Social and Behavioral Sciences 195, 20152298 - 2305.
[17] K.Zamoum and T. S. Gorpe (June 27th 2018). Crisis Management: A Historical and Conceptual Approach for a Better Understanding of Today's Crises, Crisis Management - Theory and Practice, K. Holla, M.TitkoJ.Ristvej, IntechOpen, DOI: 10.5772/intechopen.76198. Available from: https://www.intechopen.com/books/crisismanagement-theory-and-practice/crisis-management-a-historical-andconceptual-approach-for-a-better-understanding-of-today-s-crises.

[18] T.A.Williams, D.A.Gruber, K.M.Stucliffe, D.A.Shepherd, E.Y.Zhao, ORGANIZATIONAL RESPONSE TO ADVERSITY: FUSING CRISIS MANAGEMENT AND RESILIENCE RESEARCH STREAMS, Academy of Management Annals 2017, Vol. 11, No. 2 , 733-769

[19] K. M.Khalil, M. Abdel-Aziz, T.T. Nazmy, A. M.Salem, "The Role of Artificial Intelligence Technologies in Crisis Responce" ,14th International Conference on Soft Computing, June 18-20, Brno, Czech Republic., Ain Shams, 2008.

[20] M. Minges, "Disruptive technologies and their use in disaster risk reduction and management", International Telecommunication Union, Switzerland, 2019

[21] M.M. ZinOo, N. W. Zaw, D. K.S.Win, "SMS Alarm System for Weather Station using Arduino and GSM", International Journal of Trend in Scientific Research and Development (IJTSRD) ISSN: 24566470, volume 2, issue 5, 2018, pp. 1903-1907.

[22] O.Bamodua, L.Xia, L.Tang, "An indoor environment monitoring system using low-cost sensor network", 4th International Conference on Power and Energy Systems Engineering, CPESE 2017, 25-29 September 2017, Berlin, Germany, Energy Procedia 141 (2017)660666

[23] A.Mohini, "Microcontroller Based Orbital Motion Shaker", International Conference on Emerging Trends in Engineering, Science and Technology (ICETEST - 2015), Procedia Technology 24 (2016) $1194-1202$

[24] O. Bamodu, F. Osebor, L. Xia, A. Cheshmehzangi, L. Tang, "An Indoor environment monitoring based on humidity conditions using a low-cost sensor network", Applied Energy Symposium and Forum, Renewable Energy Integration with Mini/Microgrids, REM 2017, 18 20 October 2017, Tianjin, China, Energy Procedia 145 (2018) 464 471 .

[25] I.swanto, K. Purwanto, W. Hastuti, A. Prabowo, M.Y.Mustar, " Smart Smoking Area based on Fuzzy Decision Tree Algorithm", (IJACSA) International Journal of Advanced Computer Science and Applications,, Vol. 10, No. 6, 2019

[26] A. SUBBIAH, P. CHIRANJEEVI, K. SHANMUGANATHAN, C. VIGNESH, "FIRE SAFETY ROBOT", Int. J. Chem. Sci.: 14(S3), $2016,845-848$

[27] How to detect concentration of Gas by using MQ2 sensor [online https://www.instructables.com/id/How-to-Detect-Concentration-ofGas-by-Using-MQ2-Se/

[28] V.Pandya, D. Shukla, "GSM Modem Based Data Acquisition System", International Journal Of Computational Engineering Research (ijceronline.com) Vol. 2 Issue.5, September| 2012, pp. 1662 1667.

[29] How to Interface GSM Module to Arduino- send and Receive SMS [online] http://www.circuitstoday.com/interface-gsm-module-witharduino

[30] U.Chouinard, D.C.A.Pigosso, T.C.McAloone, L.Baron, S.Achiche, "Potential of circular economy implementation in the mechatronics industry: An exploratory research", Journal of Cleaner Production 239 (2019) 118014

[31] M.Popovchenko, "Introduction to Mechatronics and Mechatronics in Real Life", May 29, 2006.

[32] O.T.Nkamgang, D.Tchiotsop, H. B.Fotsin, P. K.Tallac, V. L.Dorr, D Wolf, "Automating the clinical stools exam using image processing integrated in an expert system", informatics in Medicine Unlocked 15 (2019) 100165

[33] S.Qiu, M.Sallak, W.Schön, H. X.G.Ming, " A valuation-based system approach for risk assessment of belief rule-base d expert systems", Information Sciences 466 (2018) 323-336.

[34] I.M.AHMED, M.ALFONSE, M.AREF, A.M.SALEM, "Reasoning Techniques for Diabetics Expert Systems", Procedia Compute Science 65 (2015) $813-820$

[35] N.S.Hussein, M.J.Aqel, "ESTJ: An Expert System for Tourism in Jordan", International Conference on Communication, Management and Information Technology, Procedia Computer Science 65 (2015) $821-826$ 
[36] D. İcen, S.Günay, "Design and implementation of the fuzzy expert system in Monte Carlo methods for fuzzy linear regression", Applied Soft Computing Journal 77 (2019) 399-411.

[37] M.Filter, B. Appel, A. Buschulte, "Expert systems for food safety", Current Opinion in Food Science, vol.6, 2015, pp.61-65.

[38] D.R.Wijaya, R.Sarno, E.Zulaika , S.I.Sabila, "Development of mobile electronic nose for beef quality monitoring", 4th Information Systems International Conference 2017, ISICO 2017, 6-8 November 2017, Bali, Indonesia, Procedia Computer Science 124 (2017) 728-735. 